\title{
Article
}

\section{Museums - from local to global}

\author{
Matteo Bisanti
}

\begin{abstract}
Should one aim at presenting a local or global science perspective in construing an effective museum narration for communicating scientific and technological issues in natural science? This article will attempt to respond to this question by presenting the data of an evaluation exercise undertaken by the Trento Natural History Museum (Museo Tridentino di Scienze Naturali-MTSN) from 2009 to 2011.

The local dimension apparently lies at the heart of the museum's appeal for its visitors: they associate their mountain surroundings with the symbol of the region's identity, and appreciate in particular the efforts undertaken by the museum to communicate and conserve the mountain's environment. Indeed, in their opinion, by protecting the mountains and disseminating knowledge about them, the museum indirectly acts as a custodian of the region's own identity. However, interest in local issues far from rules out global scientific themes, whose presence is sought to complement and interact with the local discourse.
\end{abstract}

\section{Introduction}

Aside from making a major effort for the classification and conservation of living species and natural environments, one of the main purposes of natural science museums is to promote environmental awareness and contribute to the protection of natural environments, with particular reference to the territory surrounding the museum.

Furthermore, nowadays it is also necessary to promote sustainable development, bringing economy and ecology closer together. The Museum must therefore also disseminate among citizens and visitors knowledge and awareness regarding natural science issues and environmental conservation. Furthermore, in the era of globalisation there is a great need to enhance local efforts and specific territorial peculiarities without, nevertheless, neglecting the world's great scientific problems with its local consequences.

Just how can all of this be communicated effectively? How to best address the relation between the local and global dimensions in the museum narration? What scientific dimension should be preferred: the local dimension of a territorial science or a global one that addresses large scale problems such as global warming or deforestation? Which of these is best suited to achieving the museum's communication objectives?

This article illustrates the results of the research work undertaken for a dissertation thesis (discussed in February 2011). The research was conducted with the cooperation of the visitors of the MTSN for the purpose of investigating their experience, opinions and preferences with reference to the "local science vs. global science" issue.

The MTSN was adopted as a case study by virtue of both its past history and the transformations it is to undergo in the near future (the new science centre MUSE), that make the focus on local aspects coupled with a drive towards global issues an intrinsic feature of the Museum. Its very name "Tridentino" (now abandoned but still in use when the evaluation was conducted) stresses the museum's connections with its surroundings. The MTSN is particularly lively and very well known to Trento's inhabitants, and lies at the heart of a network of small museums and local public gardens whose activities it fosters. Lastly, it is an important scientific research centre in natural science studies that promotes the conservation of the territory's natural habitat. The MTSN has been at the centre of a transformation triggered in the 1990s and to be completed in the next few years with the opening of the MUSE, Museo delle Scienze (Science Museum) which will replace the MTSN. This inevitably places it in a more global perspective, completing a transition from the local to the global dimension. 
The research conducted at the MTSN was divided into two steps: the first consisting in a summative evaluation of the permanent exhibition rooms (opened in autumn 2009), followed by a front-end evaluation by means of 11 interviews to museum visitors: teachers, students, habitual visitors above and below 30 years of age, both male and female, all from Trento. ${ }^{2}$ The summative evaluation focussed on visitors' preferences with regard to specific museum rooms and exhibits, not necessarily in connection with the local vs. global theme, but rather providing useful indications with reference to the most appropriate communication instruments. The summative evaluation and the observation and analysis of the questionnaires on museum rooms submitted to visitors thus made it possible to single out the criticalities concerning museum rooms and the subjects dealt with which were further addressed in the second, qualitative stage of the survey.

The questionnaire filled in by visitors in the summative evaluation stage included a question on the motivations for visiting the museum (why are you visiting the new rooms?). The results (in 169 cases the visitors replied science in general, 118 said to have a good time, 80 for the Trentino environment, a lot less for the remaining options), indicate that motivations connected with interest in the local aspect is considerable but does not prevail. The importance of the local dimension therefore does not seem to be topmost on visitor's minds, since this option was selected only half the number of times as science in general.

As the data collected on this issue proved to be very different from initial expectations, the front-end evaluation returned on this particular point in the second part of the project, in order to collect suggestions, ideas and useful information to confir previous intuitions (from the first part of the project) or to direct the study towards a further examination of the relation between the local and global dimensions.

This survey certainly cannot claim to be exhaustive on this subject, but rather wishes to encourage a discussion, and therefore claims to be a starting point towards further developments. In this respect, the new MUSE shall provide a good case study.

\section{Local}

The data collected with the summative evaluation (the first stage of the survey) show that the local dimension is very dear to museum visitors: the subjects they would like to return upon after visiting the museum are all related to the local dimension of the Trentino region, with particular reference to animals and plants of the Alps, a response that obtained the greatest number of votes within a range of ten possible answers.

Results stress that the exhibits and the thematic areas devoted to alpine environments are dearest to the public. The museum room that was most appreciated was dedicated to alpine environments, combining both classical dioramas and modern multimedia objects called interactive panoramas. This would seem to indicate that visitor's preferences have shifted towards the local dimension. Nevertheless, one should bear in mind that although they refer to an environment that is geographically familiar to the visitors, they do not indicate any specific place in particular. The room dedicated to the Tovel lake, which therefore refers specifically to the local dimension, does not seem to attract many visitors. This may be due to the fact that it describes the MTSN research on that area, but it apparently does not seem to convey effectively any scientific message, which is certainly food for thought on this issue.

Given the data produced by the summative evaluation, the local vs. global relation does not seem to be sufficient to account for results obtained, which is why the front-end evaluation was opted for in the second stage of the survey by means of interviews.

An analysis of the interviews reveals that the local dimension of science of the museum is found by visitors to be essential, crucial and not to be neglected:

\section{Science high school teacher}

It is crucial that the museum speak about the natural environment in Trentino, particularly to the local population. I believe it is essential to provide information about nature in Trentino. I have also been in laboratories on biodiversity in tropical rainforests which I found to be extremely interesting and which dealt with fascinating issues. However, I think it is imperative to start with our own environment. 
Furthermore, interviewed visitors assigned great importance to the museum's detached sites, which points out that this dimension is not to be overlooked in the museum narration. Museums should therefore give considerable importance to specific territorial realities that are viewed as scientifically interesting and which citizens are particularly proud of, expecting the museum to be supportive in enhancing them.

\begin{abstract}
Adult visitor:
... not neglecting local aspects. Just like the detached sites, for example the pile dwellings in Ledro. That is obviously a local phenomenon and therefore all the subjects raised by the museum are undoubtedly specific for that context. That is a correct and interesting approach to that environment. [...] The Caproni museum is somewhat different, perhaps because of the subject matter. Yet it is dedicated to someone from Trentino and, therefore, other people from the same region will say "one of us has achieved something in aviation" and they will always be very pleased to visit the museum.
\end{abstract}

\title{
Science high school teacher:
}

Trento, thanks to the different local sections of the museum, like for instance the Giardino delle Viotte, etc., can offer visitors out-of-doors laboratories, which I believe are quite remarkable. These sites can be reached very quickly and, hence, out-door experiences with students can be easily organised. I have taken mine along the lichens tour in Bondone, I have conducted studies on biodiversity and have taken samples of macroinvertebrates in the streams near Trento.

\section{Science junior high school teacher:}

Very year I go to the Tovel lake to experience the lake environment, which is quite magnificent. I have been going there for four years, to my great satisfaction and with excellent results each time. A wonderful experience I make every year is the Arco Arboretum for an educational outing on botanics, knowledge of plants, classification, etc. It lasts all day long with one classroom group. A most positive and worthwhile experience.

Why do interviewed visitors believe it is so crucial to illustrate the local natural environment? Why do they assign such great importance to the local dimension? A few hypotheses can be made. Firstly, local nature is a symbol of places and territories. Hence, if a museum illustrates and protects the natural environment of a certain territory, it indirectly protects the identity of that place. Interviews, especially with adults, prove that the mountains are an important symbol of their identity for the people of Trentino. The mountains represent the place where these people feel they belong, also because their presence is very strongly felt in their everyday lives. Being a symbol of Trentino's identity, the natural habitat of Trentino must be preserved and the mountains must be enhanced, because by so doing one indirectly enhances local identity and culture. The museum is thus perceived to be the custodian of Trentino's identity, because of its very mission for the protection and conservation of nature and the promotion (in the sense of the enhancement) of mountains and nature.

The visitors themselves attest to this more or less indirectly:

\section{Adult visitor:}

I think that when one lives in a certain region it is important, rather than to learn about what happens, for instance, in France, or elsewhere, one should get to know not just about Trentino's natural habitat, but also about the customs and traditions of the local population, since that is the place where one lives and was born in. Understanding the region where one lives, familiarising with our background is a good thing. Sure, it's also good to know about other people and places, but I think that our own surroundings are neglected sometimes and we learn more about, let's say, Africa or America that about our own area.

\section{Young visitor:}

We have wonderful lakes, and I believe that the discovery of the flora and the fauna of our region should not be taken for granted: all regions have beautiful landscapes, including ours.

\section{Science junior high school teacher:}

It seems to me that the amount of care put into the local territory is considerable here... quite significant. Apparently, in this respect the museum makes a notable contribution, as we have also seen in some of the events we have participated in. Last year I took part in the biodiversity week in the month of May. 
Furthermore, the local dimension allows visitors to gain first-hand experience of the contact with natural areas, enabling them to engage in a "hands-on" experience on nature and therefore to live a more captivating experience compared to simply being told about nature in its global dimension. In this respect, interviewed visitors assign great importance to the onsite locations, small museums and botanical gardens, which together constitute a fundamental network of local museums.

\section{Science high school teacher:}

The natural habitat of familiar places gives one the impression that one can reach out and touch it, learn about it easily and allow us to intervene directly on the environment surrounding us. Naturally, the problems that arise thousands of kilometres away also constitute a problem, but they require global awareness and commitment to be addressed.

\section{High school student:}

It would not, of course, be appropriate not to deal with nature in Trentino. I believe that every museum should contain references to its surroundings. [...] inside a museum visitors that find elements they can relate to, and say "I've already seen this", are very pleased with their visit. If this were possible for local nature in Trentino it would be excellent.

Another question for which answers were sought in the survey among visitors is the following: what do MTSN visitors know and how do they perceive the scientific research conducted at the museum?

The results of the first stage of the survey - conducted as previously mentioned by means of a summative evaluation - had borne witness to the scarce success of scientific research conducted by the MTSN. In the second stage, the one consisting in a front-end evaluation, we sought to find further data in this respect, as well as to investigate more in general what scientific research issues appeal most to museum visitors.

Local research, that is the subjects on which research is conducted in Trentino, seems to be of interest for the interviewed visitors. However, the findings confirm that visitors have a hazy idea of scientific research conducted both within the museum and in general, ${ }^{3}$ although apparently finding out what local research is conducted appears to be important for the visitors. Yet they see a drawback in the fact that not all subjects of scientific research can be related to the research undertaken in Trentino.

\section{High school student:}

I can't remember, but having gone around in Trentino I visited the observatories, but I can't remember if at the museum there was some sort of connection or not.

High school student:

Sure, naturally I would be interested if it was all more explicit, if one could actually say "this is what we are talking about, this is what we are doing". Yes, I would be interested.

Junior high school science teacher:

I'm afraid you're catching me by surprise here... I really can't say that I recall having seen there something that I could immediately relate to... no, I couldn't say that.

\section{Adult visitor:}

When experiments are presented, the subjects of the experiments are chosen (also) by the researchers, but the reasons for the choice are often obscure. The reasons for this choice (which are intrinsically part of the research), should at least be communicated, at least indirectly, with a flyer or something, with some information, that's what I mean. In doing so one should state that the research was conducted in Trentino.

The importance that visitors assign to the local dimension thus emerges, yet they are also the first to acknowledge its limits, particularly with reference to a totally local perspective. The local dimension is appreciated but also regarded as inappropriate with reference to all scientific current issues.

\section{Adult visitor:}

Just because I live here, it doesn't necessarily mean I am only interested in... I feel like a citizen of the world, and so I am interested in a lot of things. Plus, the world is so small that you don't say... Maybe once people would say "the world beyond", but not anymore [...] I would prefer general issues to local ones but... Obviously, it's really interesting to get to know the place we live 
in, but after that you need something to extend your viewpoint, so you can get to know about the rest of the world.

\section{Global}

Adult visitors, particularly those with young children, seem to appreciate very much the fact that the museum enables them to deal with scientific and nature-related issues in a playful manner, enabling them to see "objects" (animals, exhibits or others) that they do not generally have access to in everyday life. So much the better, then, if the exhibition includes references to the local dimension, to their surroundings, because by so doing science becomes more familiar, accessible on a daily basis and therefore turns into something that can be shared with one's children.

However, the local dimension is not the only one, the global dimension also seems important. Indeed, most of the interviewed visitors acknowledged the global dimension's ability to "open up one's mindset", to project one's perspective beyond the bounds of the limited territory they live in and, possibly, to arouse the interest of visitors who come from outside that territory.

\section{Adult visitor:}

To take an interest in nature, for instance, including about its conservation. To make others understand that it's important not to destroy it. To me that seems only obvious, but I guess it isn't from what I hear.

\section{Adult visitor:}

I think the global dimension is better, in order to deal with a great number of subjects, but without neglecting the museum's own vocation, which is to start off with local territory and problems, for example the glaciers on our mountains, etc. But the topics should then be expanded to a global level.

\section{Adult female visitor:}

To start off from the centre and then extend to other sectors and levels. To establish connections because that's the only way to be able to compare one's local reality and the rest of the world.

\section{Adult visitor:}

Perhaps to introduce the sea... In order to complete the description of environments... Just a brief hint at the sea. This might be quite suitable because we come from the ice age, so I guess it's right that we should learn about the sea: you can find fossils here as well.

\section{Adult female visitor:}

If I could choose I would go for both, in a balanced manner. With several rooms available this should be possible, perhaps they already do something like this in Genoa, which is by the sea, about the sea, about life, about nature, including, if possible, about non local stuff.

In the new MUSE museum, besides the global dimension of science, which is not to be neglected according to visitors, ample attention has also been devoted to the exhibition's structure. ${ }^{4}$ This is doubtless a very good choice. Indeed, the interviews with visitors about the issues that they regard as interesting and would like to find in the museum exhibits reveal not only the traditional subjects related to nature, geology and zoology, but also topical issues which can be presented both in a local and a global perspective. For instance, among the issues mentioned in the interviews we find (besides the glaciers of the Dolomites, which have a strong local connotation) astronomy, waste and waste disposal, entomology, mineralogy, ecology, mechanics, pollution, animal extinction, technology development, genetics, cloning and several others. These a reissues that, to a certain extent, indicate visitors' interest in a global dimension of science that deals with problems at a "planetary level".

Notwithstanding, visitors are found to be aware of the risks inherent in a museum narration that exceeds with respect to the local dimension of science. Indeed, if on the one hand it is true that although a focus should be kept on the local dimension, on the other the global one is important because it enables local issues to be placed within a context, making their coverage comprehensive (including in the implications that overcome Trentino's boundaries); nonetheless, there is a greater appeal in the local dimension, 
particularly the fact that, as far as visitors are concerned, global issues may be harder to grasp and therefore offer limited opportunities for a "direct experience".

\section{Conclusion}

Therefore, for museum visitors the local and the global dimensions of science are both important, albeit to a different extent and with different proportions. The coexistence within the museum of a scientific narration that looks to the local and global dimensions is undoubtedly a factor of its success, because visitors are left with e impression that the balance between the two overcomes the flaws of both and enhances their strong points, thereby making the museum's exposition more exhaustive. In the interviews, "balance" is the word most often used by visitors to describe the kind of relation between local and global that they would like to find in the museum.

Science high school female teacher:

The right kind of balance should be stuck between "here" and the "rest", in order to place the "here" within the "rest". Indeed, we are not isolated, we belong to a global context and therefore knowledge must be global.

\section{High school student:}

There should be balance: fifty fifty. That means there should be fifty per cent of the exhibition on the natural environments of the rest of the world and fifty per cent on Trentino's. The latter should play a major role, but I wouldn't want it to prevail. I'd rather have half the museum about Trentino's and the other half about the rest.

Adult female visitor:

If I could have it my way, I would like a bit of both, so that the whole thing is balanced.

However, what dimension one should start out with and the proportions with which to deal the different scientific fields is far from clear and no individual emerging trend can be singled out. Each visitor seems to have different preferences and a lot seems to depend on the subject matter.

\section{High school student:}

I think it should be rather balanced. A bit of both. It doesn't really matter what the proportions are, that depends on the subjects one wants to deal with. Something related to nature in general and the surrounding territory is a good combination. If, on the other hand, it's something about outer space, which has no connection with Trentino, then it's pointless.

\section{High school student:}

I would go for 60-40, meaning 60 per cent for global stuff (which isn't much anyway), one might even go more in-depth and increase beyond 60 . And 40 per cent, or say 35-40 per cent dedicated to the local environment. At first glance it may not seem to be much but 40 per cent is quite a lot.

\section{Young visitor:}

I would go for 40 per cent Trentino, and say 20 per cent for Trentino emergencies, new things that happen, in the rooms available for monthly events and so on, and 40 per cent for the rest of the world, that is for bigger issues or for different things.

\section{Adult visitor:}

Since the museum surface is far from huge I think that I would divide the museum 50-50.

In order to make a conclusion and draw to an end, we could say that the interviewed visitors seem to hope for global and local to complement one another, with the great appeal of the local dimension going hand in hand with the ample perspective (albeit with different extents and proportions) afforded by the global dimension. As a result, an important suggestion arises for the design of museum exhibitions and for the work of science communicators, particularly in view of the opening of the new MUSE. 


\section{Note and references}

1 M. Bisanti (2011), La scienza tra locale e globale al Museo Tridentino di Scienze Naturali, dissertation thesis for the Master in Science Communication at SISSA (Scuola Internazionale di Studi Superiori Avanzati), February 2011.

2 For methodological references see J. Diamond (1999), Practical evaluation guide: tools for museum \& other informal educational settings, Walnut Creek CA, AltaMira Press.

3 Poor similar conclusions referring to the Darwin Centre in London see Darwin Centre Phase 2 Frontend Evaluation Report, publication by the Natural History Museum in London, November 2005.

4 Information on the MUSE and on the project contents is available on e website www.muse2012.it (website of the MUSE project, Trento)

5 M. Lanzinger (2007), Il movimento scienza e società e il progetto del MUSE, JCOM 06(2): C05 $<\mathrm{http}: / / j$ com.sissa.it/archive/06/02/Jcom0602(2007)C01/Jcom0602(2007)C05>.

6 M. Lanzinger (2004), Il Museo Tridentino Scienze Naturali verso la contemporaneità e oltre, «Natura Alpina» 55: 33-48.

7 M. Merzagora and P. Rodari (2007), La scienza in mostra. Musei, science centre e comunicazione, Milano, Mondadori.

8 P. Rodari (2005), Apprendere al museo. La costruzione del sapere come attività sociale, JCOM 04(3): R01 <http://jcom.sissa.it/archive/04/03/R040301/>.

\section{Author}

Matteo Bisanti - A biologist, he obtained a Master in Science Communication at SISSA, Trieste, Italy. He works for the University of Modena and Reggio Emilia in projects related to science museology and entomology. He mostly deals with the design of digital support instruments for museum visits and for educational laboratories. E-mail: bisantimatteo@gmail.com.

How to CITE: $\quad$ M. Bisanti, Museums - from local to global, Jcom 11(02) (2012) A01. 